\title{
An Electrophysiological Study of the Postnatal Development of the Corticospinal System in the Macaque Monkey
}

\author{
Etienne Olivier, ${ }^{1}$ Steve A. Edgley, ${ }^{2}$ Jean Armand, ${ }^{3}$ and Roger N. Lemon ${ }^{1}$ \\ ${ }^{1}$ Sobell Department of Neurophysiology, Institute of Neurology, London WC1N 3BG, United Kingdom, ${ }^{2}$ Department of \\ Anatomy, Cambridge University, Cambridge CB2 3DY, United Kingdom, and ${ }^{3}$ Centre National de la Recherche \\ Scientifique, Laboratoire de Neurosciences Cognitives, 13402 Marseille Cedex 20, France
}

Postnatal development of the corticospinal system was investigated in 13 macaques using noninvasive transcranial magnetic stimulation (TMS) of the motor cortex and direct electrical stimulation of corticospinal axons in the medullary pyramid and spinal cord. The latency of antidromic corticospinal volleys evoked from the pyramid and recorded from the motor cortex decreased dramatically during the first postnatal months. Our data predict that conduction velocity $(\mathrm{CV})$ of the fastest corticospinal neurons over their cranial course would reach adult values at $\sim 11$ months. The CV of corticospinal neurons in the spinal cord increased with age but with a slower time course. In the neonate, the fastest spinal CV was estimated at $7.8 \mathrm{~m} / \mathrm{sec}$, $\sim 10$ times slower than in adults (mean $80.0 \mathrm{~m} / \mathrm{sec}$ ). Our data predict that full myelination of corticospinal axons in the spinal cord would not occur until $\sim 36$ months. No short-latency EMG responses were elicited in arm and hand muscles by TMS until
3 months of age; TMS thresholds were high initially and then fell progressively with age. When corrected for body size, relative latencies of EMG responses showed an exponential decrease during the first postnatal months.

Our data are consistent with the hypothesis that fine finger movements are not observed before functional CM connections are well established and that rapid changes in the physiological properties of the corticospinal system coincide with the period in which precision grip is known to mature (3-6 months). However, corticospinal development continues long after simple measures of dexterity indicate functional maturity, and these changes may contribute to the improved speed and coordination of skilled hand tasks.

Key words: corticospinal system; pyramidal tract; macaque monkey; development; motor cortex; precision grip
Among the primate order, the index of dexterity and use of relatively independent finger movements (RIFM) is thought to reflect the degree to which motoneurons innervating the muscles acting on hand and fingers receive direct, monosynaptic projections from the cerebral cortex (Phillips, 1971; Heffner and Masterton, 1975, 1983; Kuypers, 1981; Bortoff and Strick, 1993) (see pp. 90-96 in Porter and Lemon, 1993). These corticomotoneuronal $(\mathrm{CM})$ projections are weak or absent among the lower primates, such as the lemur and in some New World monkeys, and show a progressive increase in density from Old World monkeys through apes to human.

Further evidence for an involvement of CM projections in the performance of RIFM has been sought by attempting to correlate the ontogeny of the corticospinal system with the development of skilled finger movements in infants. In his anterograde degeneration study, Kuypers (1962) could find no significant corticospinal terminations among the motor nuclei of a neonatal macaque, and he suggested that the inability to perform RIFM at birth was in part attributable to the immaturity of the CM projection. This hypothesis was supported by behavioral studies: Hinde et al.

Received June 19, 1996; revised Sept. 6, 1996; accepted Oct. 2, 1996.

This work was supported by The Wellcome Trust, Brain Research Trust, Action Research, and by a Royal Society-Centre National de la Recherche Scientifique exchange grant. We acknowledge the expert assistance of Rosalyn Cummings, Nora Philbin, Stuart Baker, Marc Maier, Michael Simpson, and Chris Seers.

Correspondence should be addressed to Prof. Roger Lemon, Sobell Department of Neurophysiology, Institute of Neurology, Queen Square, London WC1N 3BG, UK.

Dr. Olivier's present address: NEFY 5449, Laboratory of Neurophysiology, University of Louvain, Avenue Hippocrate 54, B-1200 Brussels, Belgium.

Copyright (C) 1996 Society for Neuroscience $0270-6474 / 96 / 170267-10 \$ 05.00 / 0$
(1964) observed that grooming, for which RIFM are essential, was not observed in infant macaques until $\sim 6$ months. In their classic study, Lawrence and Hopkins (1976), reported that the earliest signs of RIFM occurred at 2-3 months, with a mature pattern at 7-8 months. Galea and Darian-Smith (1995) recently reported that performance on a reach-and-grasp test by a group of young macaques approached adult levels by $\sim 6$ months. This correlated with the emergence of an adult-like distribution of cortical motor areas contributing to the corticospinal tract.

In our preceding study (Armand et al., 1996b), we used the wheat germ agglutin-horseradish peroxidase technique to label $\mathrm{CM}$ projections from primary motor cortex (M1). Our results showed that the CM projection is weak or absent at birth. Although it develops rapidly in the first few postnatal months, it does not mature fully until the second year of life. Thus, from an anatomical viewpoint, the development of the CM system is very protracted, but we have very little information on its physiological maturation: its ability to carry impulses and the effects of these impulses on target motoneurons supplying hand and finger muscles.

Recent studies have used transcranial magnetic stimulation (TMS) of the motor cortex to explore maturation of the primate corticospinal system by studying the threshold and latency of muscle responses (Eyre et al., 1991; Müller et al., 1991, 1994; Flament et al., 1992). In the infant macaque, Flament et al. (1992) reported that the earliest component of EMG responses to TMS, which in the adult is mediated by the CM system (Edgley et al., 1990; Baker et al., 1994), could not be obtained before 2-3 months of age. Thereafter, the threshold of EMG responses to TMS 
Table 1.

\begin{tabular}{|c|c|c|c|c|c|c|}
\hline & Case & Age & $\begin{array}{l}\text { Weight } \\
(\mathrm{kg})\end{array}$ & $\begin{array}{l}\text { Cranial course } \\
\text { (antidromic latency in } \\
\text { msec, PT to cortex) }\end{array}$ & $\begin{array}{l}\text { Spinal course } \\
\text { (conduction velocity } \\
\text { in } \mathrm{m} / \mathrm{sec} \text { ) }\end{array}$ & $\begin{array}{l}\text { EMG } \\
\text { responses } \\
\text { to TMS }\end{array}$ \\
\hline Neonate & 7 & $5 \mathrm{~d}$ & 0.6 & NA & $7.8^{a}$ & absent \\
\hline & 11 & 2.5 months & 0.7 & 1.98 & 28.4 & $\checkmark$ \\
\hline & 2 & 3 months & 0.7 & NA & 35.6 & $\sqrt{ }$ \\
\hline & 5 & 5 months & 0.8 & 1.60 & 41.3 & $\checkmark$ \\
\hline & 8 & 11 months & 2.9 & 0.68 & 51.4 & $\sqrt{ }$ \\
\hline & 10 & 13 months & 2.5 & 0.85 & 55.4 & $\checkmark$ \\
\hline \multirow[t]{3}{*}{ Adults } & 6 & 3 years & 2.1 & 0.78 & 72.2 & $\checkmark$ \\
\hline & 1 & 3 years & 2.3 & 0.84 & NA & $\checkmark$ \\
\hline & 12 & 12 years & 5.9 & 0.65 & 83.7 & $\sqrt{ }$ \\
\hline
\end{tabular}

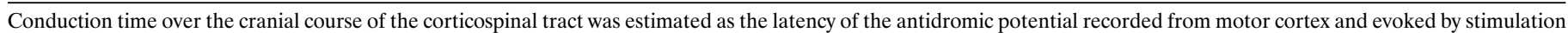
of the medullary PT. Conduction velocity over the spinal course was determined from orthodromic volleys excited from the PT and recorded at different spinal levels. ${ }^{a}$ In this case, $\mathrm{CV}$ was estimated from the latency difference between antidromic volleys recorded from motor cortex and evoked from different spinal levels.

declined rapidly, so that by 5-8 months threshold values were similar to those observed in adults. By 8 months, the long-latency EMG responses of the 3-month-old infant had shortened to adult values. However, because an 8-month-old rhesus monkey measures only about half of its adult size (see Schultz, 1933), it is probable that the $\mathrm{CV}$ of corticospinal neurons continues to increase as the monkey grows, as suggested by TMS studies of human infants (Eyre et al., 1991; Müller et al., 1991, 1994) (see Armand et al., 1996a). However, this conclusion is based on indirect evidence, and no direct measurements of CV of corticospinal axons in the developing primate have yet been made.

The aim of the present study was to assess changes in $\mathrm{CV}$ of corticospinal axons at both the cranial and the spinal levels in the developing macaque. These data have been compared with the latency and threshold of upper limb EMG responses evoked by the TMS of the motor cortex in the same monkeys. These neurophysiological assessments have been analyzed in the light of anatomical data, again from the same animals, on the maturation of corticospinal projections to the cervical enlargement (see Armand et al., 1996b).

Preliminary accounts have been published previously (Armand et al., 1994; Olivier et al., 1994).

\section{MATERIALS AND METHODS}

This study was performed in 13 purpose-bred Macaca fascicularis or Macaca mulatta, including one neonate $(5 \mathrm{~d}), 8$ young infants, and 4 adults (see Table 1 for details). Most of these animals were also used for an anterograde labeling study of developing corticospinal projections [see companion paper (Armand et al., 1996b)]. Electrophysiological observations were made on the side contralateral to that used for the neuroanatomical study.

Anesthesia was induced with ketamine $(10 \mathrm{mg} / \mathrm{kg}$, i.m.), supplemented as required. Monkeys were placed in a hammock, which allowed stabilization of the head during this part of the experiment. TMS was delivered from a Magstim 200 stimulator (maximum output 2.2 Tesla) using a standard round coil (diameter $14 \mathrm{~cm}$ ) centered over the hand area of the motor cortex. Surface EMG activity was recorded from the contralateral extensor digitorum communis (EDC) and first dorsal interosseous (1DI). The coil position was adjusted to obtain the largest EMG responses for a given intensity, and then the threshold was determined by progressively decreasing stimulus intensity. The threshold was arbitrarily defined as the lowest intensity for which the probability of EMG responses to TMS was $\geq 0.2$. TMS was performed on only two adults (see Table 1 ).
General anesthesia was then induced and maintained using 2-3\% isoflurane in a 50:50 $\mathrm{O}_{2} / \mathrm{N}_{2} \mathrm{O}$ mixture. Body temperature was carefully maintained at $37-38^{\circ} \mathrm{C}$. Two varnish-insulated tungsten electrodes (tip impedance $\sim 20 \mathrm{k} \Omega$ at $1 \mathrm{kHz}$ ) were implanted under stereotaxic control $5 \mathrm{~mm}$ apart in the medullary pyramidal tract (PT), usually at P1 and P6. Electrodes were positioned at the lowest threshold point for evoking an antidromic volley, recorded from the surface of the ipsilateral motor cortex. Thresholds ranged from 20 to $100 \mu \mathrm{A}$ (duration 0.1 or $0.2 \mathrm{msec}$ ). Correct placement of electrodes was subsequently confirmed by postmortem histological analysis (see Edgley et al., 1990). The antidromic nature of these potentials was confirmed by showing that they could faithfully follow high frequencies of stimulation (typically 3 pulses at $200-300 \mathrm{~Hz}$ ) without any noticeable change in shape, amplitude, or latency. The latency of these antidromic potentials was used as an indicator of $\mathrm{CV}$ changes in the corticospinal tract over its cranial course.

To measure the $\mathrm{CV}$ of corticospinal axons over their spinal course, two small laminectomies were then performed at different spinal levels, usually at low cervical and low thoracic levels (Fig. 1). The dura was opened, and orthodromic corticospinal volleys evoked by PT stimulation were recorded simultaneously from the surface of the dorsolateral funiculus (DLF) with silver ball electrodes. The distance between the two recording sites was carefully measured both before and after perfusion of the animal. A further estimate of the CV of corticospinal neurons in the spinal cord was obtained by inserting a fine varnish-insulated tungsten electrode into the DLF to excite corticospinal axons and then recording the antidromic volleys from the surface of the contralateral motor cortex (Fig. 1). This approach yielded almost the same estimate of the corticospinal axon CV as that obtained from orthodromic volleys evoked by PT stimulation. This was confirmed by regression analysis (slope $=1.09, r^{2}=$ $0.98, p<0.001, n=5$ ). In the neonate (case 7), no PT electrodes were implanted, and CV estimates were based solely on the antidromic measurements.

Analysis. All signals were both digitized on-line and recorded on tape for further off-line analysis. Corticospinal volleys and EMG activity were digitized at 80 and $5 \mathrm{kHz}$, respectively. Latencies of EMG responses to TMS were measured on every individual trace and then used to calculate the mean and SD. Given the variability of these latencies $(\mathrm{CV} \sim 10 \%)$, the 10th percentile of the latencies was used to determine the minimum conduction time from the motor cortex to muscles. This method was preferred to the use of the shortest latency of EMG response to minimize possible error. EMG response latencies were also normalized for the size of the animals by dividing latencies by the cubic root of the body weight. The validity of this approach has been tested on data published by Schultz (1933) by performing a regression analysis between sitting height and cubic root of body weight $\left(r^{2}=0.99, n=30\right)$ for rhesus monkeys aged from birth to 92 months.

Corticospinal volleys were averaged (usually $n=100$ ), and both onset 
Rec.

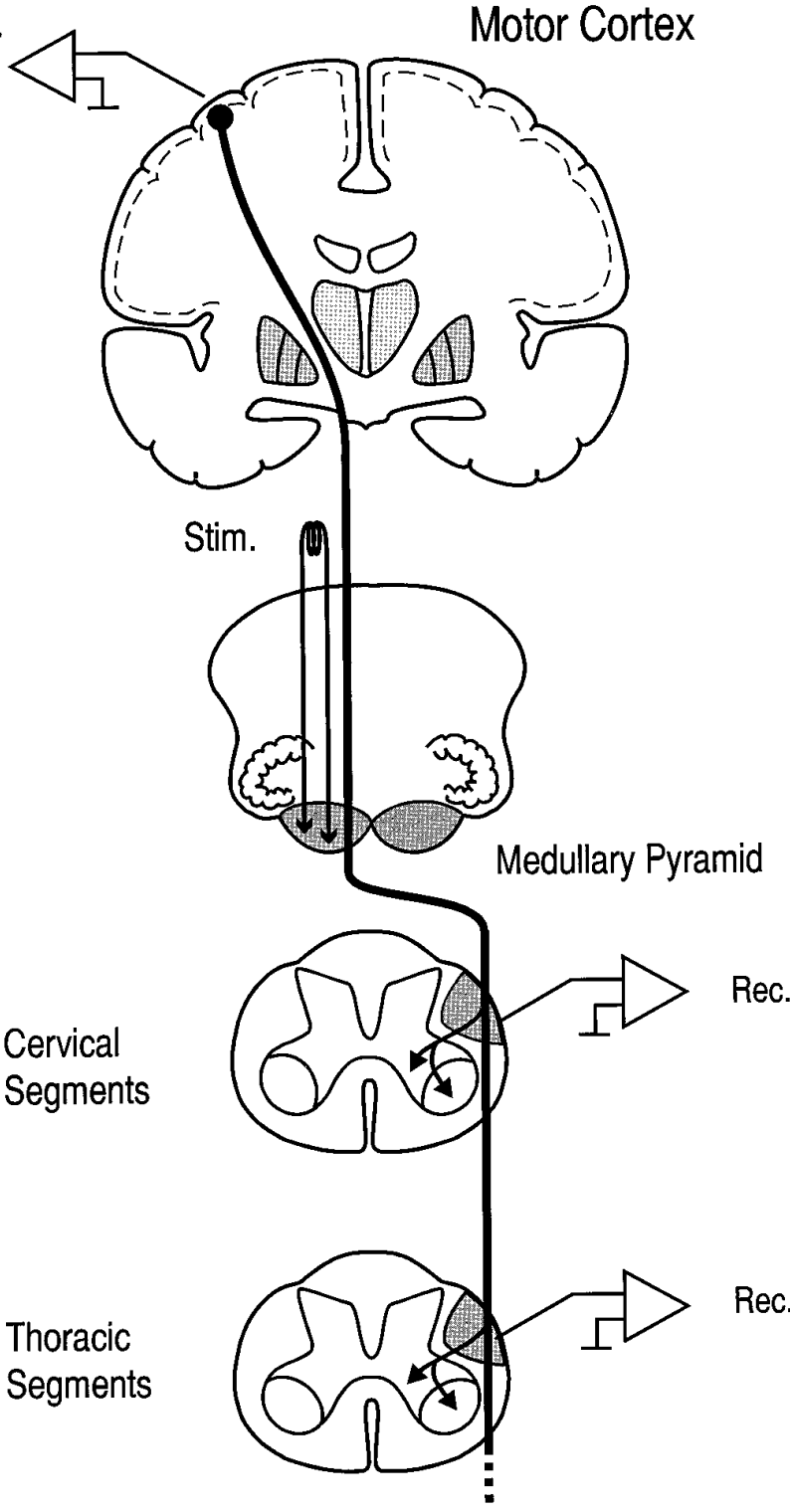

Figure 1. Schematic view of acute experiments. Two stimulating electrodes were implanted in the medullary pyramidal tract (PT), usually at antero-posterior stereotaxic levels P1 and P6. Antidromic volleys were recorded from the surface of the exposed motor cortex with silver ball electrodes. Orthodromic volleys, evoked by PT stimulation, were recorded from the surface of the dorso-lateral funiculus, usually at low cervical and low thoracic levels. The distance between the two recording sites was carefully measured to estimate conduction velocity of corticospinal axons over their spinal course.

and peak latencies of the first positive inflection were measured on volleys obtained with stimulus intensities of about twice threshold.

\section{RESULTS}

\section{Age-related changes in conduction velocity of corticospinal neurons}

Antidromic corticospinal volleys recorded from the motor cortex Figure 2 illustrates averaged antidromic volleys recorded from the surface of the ipsilateral motor cortex and evoked by stimulation of corticospinal axons in the pyramid in one adult and in the 11-, 9-, and 2.5-month-old monkeys. In the adult, the onset and peak latencies of this antidromic volley were 0.78 and $1.04 \mathrm{msec}$, respectively. These values were similar to those obtained in the
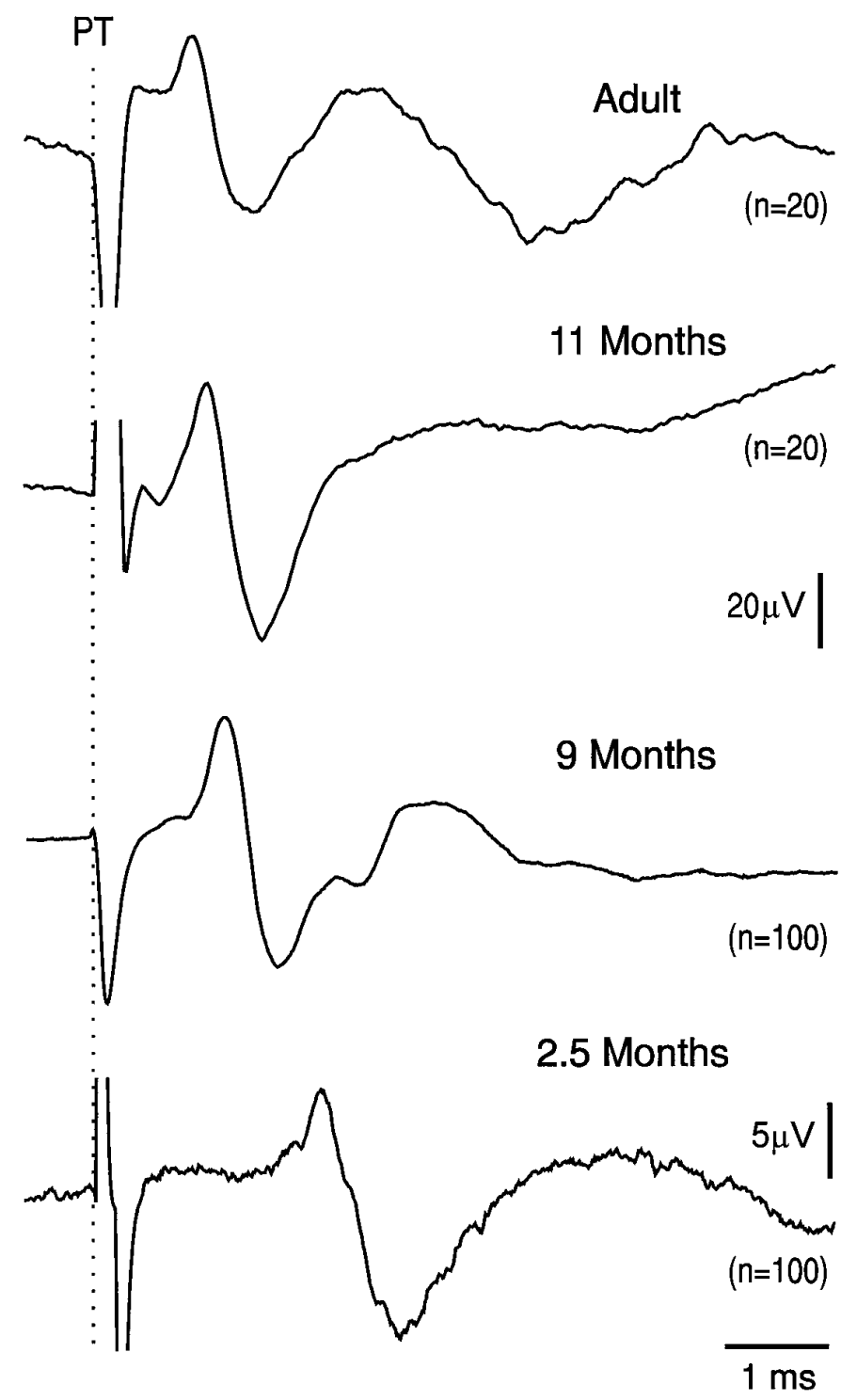

Figure 2. Averaged records of antidromic volleys evoked from the medullary pyramidal tract $(P T)$ stimulation and recorded from the hand area of the motor cortex in one adult (case 6, 36 months old) and in the 11-, 9-, and 2.5-month-old infant monkey. Volleys were evoked from the posterior PT electrode (located at stereotaxic level P6) with an intensity twice the threshold. Vertical dotted line indicates the onset of PT stimulation. $n$, Number of sweeps in average. Note higher gain in the 2.5-month-old monkey.

other adults after stimulation through the most caudal PT electrode: the mean onset latency was $0.77 \mathrm{msec}$ (range $0.65-0.84$ msec, $n=4$ ), and the mean peak latency $1.04 \mathrm{msec}$ (range $0.94-1.14, n=4)$.

In the 11-month-old animal, the onset and peak antidromic latencies were 0.68 and $1.13 \mathrm{msec}$, respectively. These values were within the range of adult values given above. In younger animals, both onset and peak latencies of antidromic volleys were considerably longer than those obtained in adults. For example, in the 9-month-old monkey the onset and peak latencies were 0.96 and $1.30 \mathrm{msec}$, respectively. At 2.5 months, the antidromic volley was even more delayed, with onset and peak latencies of 1.98 and 2.30 msec, respectively.

Figure $3 A$ illustrates successive antidromic corticospinal volleys 
evoked by three shocks delivered at $\sim 250 \mathrm{~Hz}$ and recorded in the 1-month-old monkey. The onset latency was $1.85 \mathrm{msec}$, and the consistency of the responses is illustrated by the superimposed traces in Figure $3 B$. It can be seen that the volleys follow faithfully the high frequency of stimulation, demonstrating that corticospinal axons in infant monkeys are already able to convey highfrequency repetitive discharges (see Discussion).

The relationship between age and onset latency of antidromic volleys evoked from posterior PT electrodes is illustrated in Figure $4 A$. Because the macaque brain has been shown to reach its adult size as early as $2-3$ months (Holt et al., 1975), it can be assumed than the conduction distance between the cortex and pyramid is constant among all monkeys except for the 1-monthold animal (Fig. $4 A, \mathbf{\square}$ ). Therefore, volley latencies can be compared directly without normalization for conduction distance.

Figure $4 A$ indicates that $C V$ of corticospinal axons over their cranial course increases exponentially during the first postnatal months. The negative exponential function that best fits the data and that is plotted in Figure $4 A$ has a time constant of 3.8 months. This equation predicts that the $\mathrm{CV}$ of corticospinal axons over their cranial course should reach a value within the adult range by 11.4 months (3 time constants).

\section{Orthodromic corticospinal volleys recorded from the spinal cord}

Figure $5 \mathrm{~A}$ illustrates the orthodromic corticospinal volleys recorded in one adult monkey from the lower cervical (C6) and lower thoracic (Th9) spinal segments. These volleys were elicited by a $100 \mu \mathrm{A}$ stimulus (duration $0.2 \mathrm{msec}$ ) delivered through the posterior PT electrode. The peak latency of volleys recorded at the C6 and Th9 levels was 0.75 and $2.10 \mathrm{msec}$, respectively. The $\mathrm{CV}$ of the axons contributing to this spinal volley was estimated at $83.7 \mathrm{~m} / \mathrm{sec}$ (conduction distance $113 \mathrm{~mm}$ ). In the two other adults, the corticospinal $\mathrm{CV}$ in the spinal cord was estimated at 72.2 and $84.2 \mathrm{~m} / \mathrm{sec}$, respectively (mean $80.0 \mathrm{~m} / \mathrm{sec}$ ).

In infant animals, the $\mathrm{CV}$ of the fastest corticospinal axons within the spinal cord was much slower. This is illustrated for the 1-month-old monkey (Fig. 5B). Orthodromic volleys were evoked from the anterior PT electrode and recorded at the low cervical (C7) and low thoracic (T9) segments. The peak latency of the corticospinal volleys was 1.4 and $3.6 \mathrm{msec}$, respectively, and yielded an estimate for the $\mathrm{CV}$ of the fastest axons in the spinal cord at $20.1 \mathrm{~m} / \mathrm{sec}$ (conduction distance $44 \mathrm{~mm}$ ). Even in the 13-month-old animal, the $\mathrm{CV}$ was still slower than in the adults $(55.4 \mathrm{~m} / \mathrm{sec})$.

In the neonate, the corticospinal $\mathrm{CV}$ in the spinal cord was estimated from the difference in latencies of antidromic volleys recorded from the surface of the motor cortex after stimulation of the DLF at C7 and Th8 (see Materials and Methods). The onset latency of these volleys was 2.05 and $9.27 \mathrm{msec}$, respectively. Conduction velocity of the fastest corticospinal axons in the spinal cord was estimated at $7.8 \mathrm{~m} / \mathrm{sec}$, i.e., $>10$ times slower than the mean value found in adult monkeys. Even in this newborn monkey, the corticospinal axons could follow stimuli up to a frequency of $\sim 200 \mathrm{~Hz}$.

The relationship between age and $\mathrm{CV}$ of corticospinal axons over their spinal course is summarized in Figure $4 B$. The negative exponential that best fits this relationship, and which is plotted in Figure $4 B$, has a time constant of 11.6 months. This equation predicts that the $\mathrm{CV}$ should reach a value within the adult range by $\sim 36$ months (3 time constants).
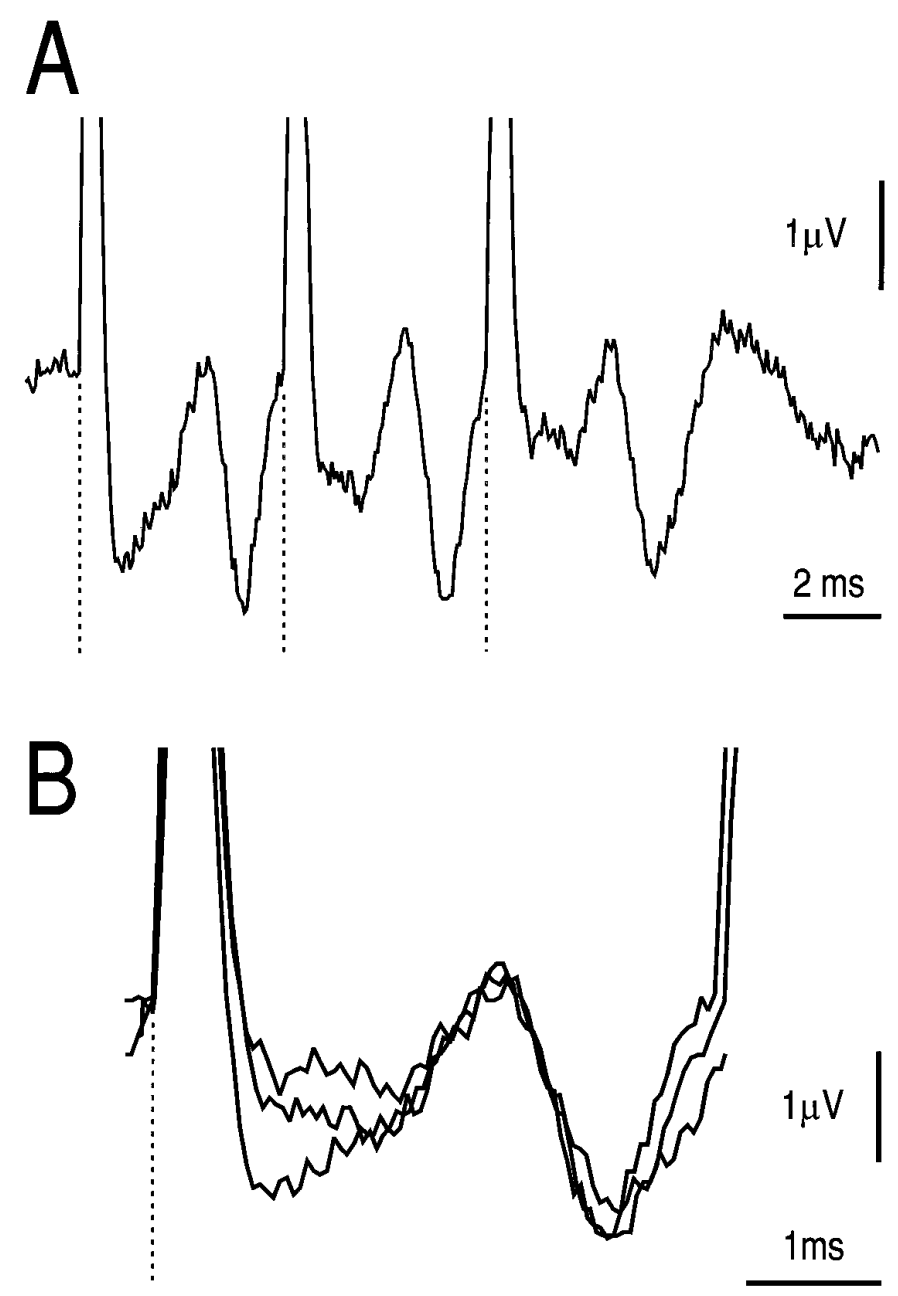

Figure 3. A, Averaged records $(n=106)$ of the successive antidromic volleys evoked by a train of three PT stimuli at $250 \mathrm{~Hz}$ and recorded from the surface of motor cortex in the 1-month-old monkey (case 15). B, Same averaged antidromic volleys superimposed and aligned on the onset of PT stimulation artifact to show consistency of responses. Vertical dashed lines indicate onset of PT stimulation.

\section{EMG responses to transcranial magnetic stimulation} Age-related changes in latency of EMG responses

Figure $6 A$ illustrates the difference in latencies of 1DI responses to TMS in an adult (case 6) and in the 3-month-old monkey (case 2). Despite a much larger conduction distance from the motor cortex to hand muscles in the adult, the onset latency of EMG response was shorter in the adult (mean $\pm \mathrm{SD}, 9.5 \pm 1.0 \mathrm{msec}$, $n=54)$ than in the 3-month-old animal $(12.90 \pm 1.0 \mathrm{msec}, n=$ 12). This difference in latencies was even larger when the shortest latencies of EMG responses (see Materials and Methods) were considered (adult, $8.0 \mathrm{msec}$; 3-month-old, $12.0 \mathrm{msec}$ ). In the other, larger adult investigated (case 14; see Table 1), the shortest latency of 1DI responses to TMS was $10.3 \mathrm{msec}$.

Figure $6 B$ illustrates the relationship between age and shortest latency of EMG responses recorded from 1DI and EDC for 8 animals. Despite the fact that most of the infants were smaller than the adults, EMG responses in 1DI and EDC had a somewhat longer latency in the infants. This suggests that the overall $\mathrm{CV}$ between the motor cortex and hand muscles must increase with age. The 13-month-old monkey (case 10) is the exception that proves the rule: this animal was a $M$. mulatta 

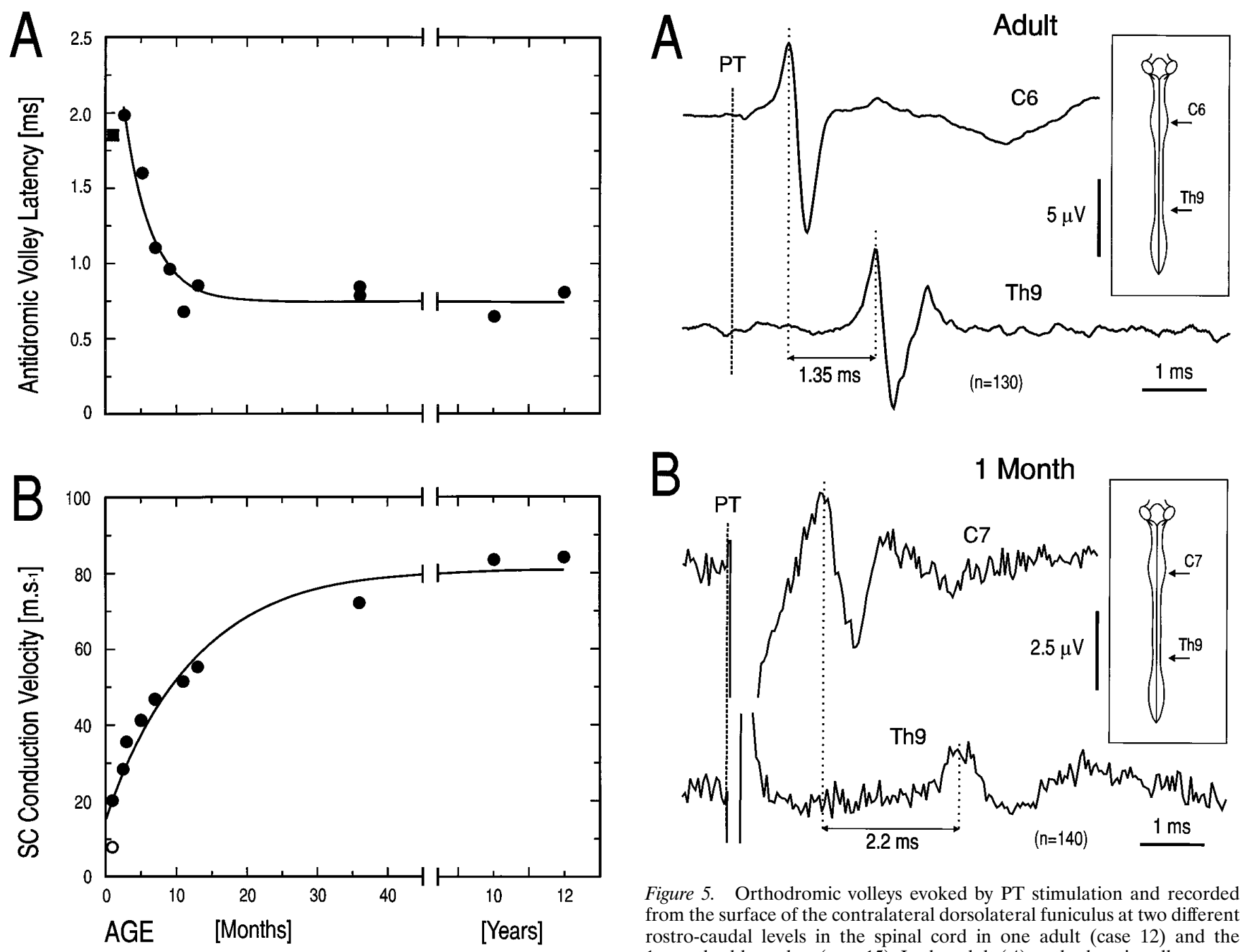

Figure 5. Orthodromic volleys evoked by PT stimulation and recorded from the surface of the contralateral dorsolateral funiculus at two different rostro-caudal levels in the spinal cord in one adult (case 12) and the 1-month-old monkey (case 15). In the adult $(A)$, orthodromic volleys were recorded at the C6 and Th9 spinal level (average of 130 sweeps). Stimulus intensity $100 \mu \mathrm{A}$; duration $0.2 \mathrm{msec}$. Conduction delay of the volley between the two sites, which were $113 \mathrm{~mm}$ apart, was $1.35 \mathrm{msec}$. CV of the largest corticospinal axons was estimated at $83.7 \mathrm{~m} / \mathrm{sec}$. In the 1 -month-old monkey $(B)$, stimulus intensity was $200 \mu \mathrm{A}$ and duration was $0.2 \mathrm{msec}$. Volleys were recorded at C7 and Th9 (average of 140 sweeps). The conduction delay was $2.2 \mathrm{msec}$, and the conduction distance was $44 \mathrm{~mm}$. $\mathrm{CV}$ was $20.1 \mathrm{~m} / \mathrm{sec}$. Vertical dashed lines indicate the onset of PT stimulation.

(case 15): because brain size has not reached its adult value at this age, this point was not incorporated in the data used to compute the exponential. $B$, Age-related change in conduction velocity $(\mathrm{CV})$ of the fastest corticospinal axons in the spinal cord in 11 monkeys. CV was estimated from the difference in latency of orthodromic volleys recorded at two spinal levels in response to PT stimulation (filled circles). In the 5-d-old monkey (case 7), CV was estimated from the latency difference of antidromic cortical volleys evoked by stimulation of the dorsolateral funiculus at two different spinal levels and recorded from the motor cortex $(\bigcirc)$. Equation of the best-fitted exponential was $y=81.1-66.6 \exp (-0.08 x)$, where $x$ is expressed in months $(\tau=11.9$ months, $r=0.98)$.

(case 10) and was actually larger than the adult $M$. fascicularis (case 6; see Table 1). The shortest latencies of EMG responses recorded in $1 \mathrm{DI}$ were $10.4 \mathrm{msec}$ in the 13 -month-old animal and $8.0 \mathrm{msec}$ in the adult.

As a group, the infant monkeys did not exhibit any clear decline with age in their EMG response latencies. Neither of the regression lines computed between age (up to 13 months) and the shortest EMG response latencies in 1DI or EDC had a

slope significantly different from zero. However, an age-related decrease in conduction time from the motor cortex to hand muscles was confirmed by normalizing the shortest EMG response latencies with respect to body size (Fig. 7A). This relative latency value was calculated by dividing the absolute latency by the cube root of body weight (see Materials and Methods).

Assuming that conduction time from the motor cortex to 1DI and EDC motor nuclei is the same (see Jenny and Inukai, 1983), the difference between the relative latencies of EMG responses in these two muscles should provide an estimate of age-related changes in peripheral conduction velocity. Figure $7 B$ shows that this estimate of the peripheral delay shortened dramatically during the first postnatal months with a time constant of only 3.3 months, much shorter than that observed for corticospinal axons in the spinal cord. This suggests that 


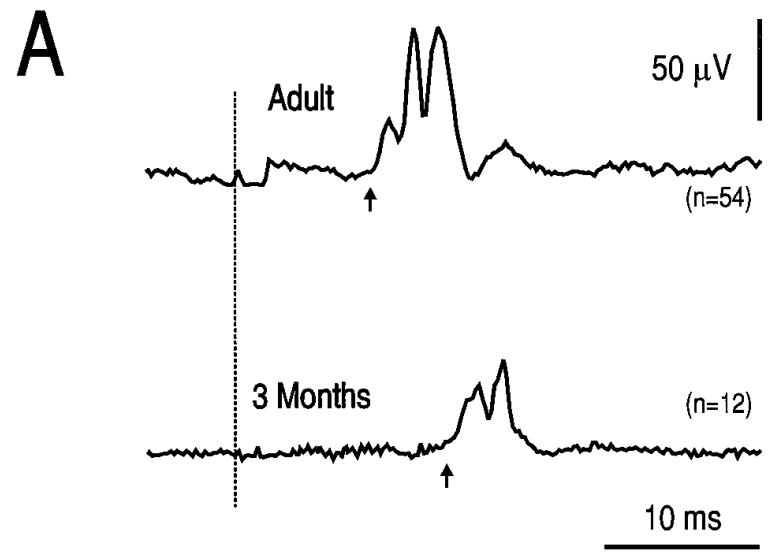

$B$

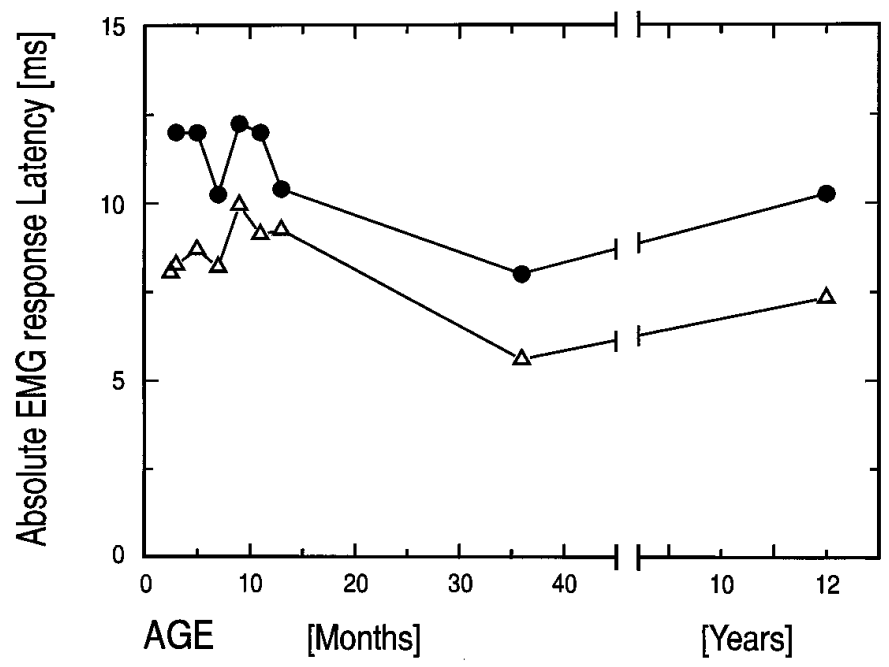

Figure 6. A, Averages of rectified EMG response to transcranial magnetic stimulation (TMS) of the motor cortex recorded in 1DI in one adult (case 6) and in the 3-month-old monkey (case 2). TMS intensity was 50\% of maximum stimulator output in the adult and $100 \%$ in the 3 -month-old. Vertical dashed line indicates the onset of TMS. $n$, Number of sweeps in average. Arrows indicate the onset of the EMG responses. B, Relationship between age and minimal latency of EMG responses in 1DI to TMS (filled circles) and EDC (open triangles). Latencies represent the mean of the 10th shortest percentile of all responses recorded (see Materials and Methods).

peripheral axons conduct at adult velocities much earlier than do corticospinal axons (as shown in human by Eyre et al., 1991).

\section{Age-related changes in threshold of EMG responses to TMS}

The threshold of EMG responses to TMS was determined for 1DI and EDC (see Materials and Methods); both showed a consistent decrease with age (see Fig. 8). The time constant of the exponential fitted to the 1DI data was 6.5 months. In the neonate and 1-month-old monkey, TMS at the maximal output of the stimulator failed to elicit any EMG responses. In the 2.5-month-old monkey, maximal TMS produced responses in EDC but not in 1DI. EMG responses to TMS were first observed in 1DI in the 3-month-old monkey. The threshold of 1DI was generally slightly higher than that of EDC.
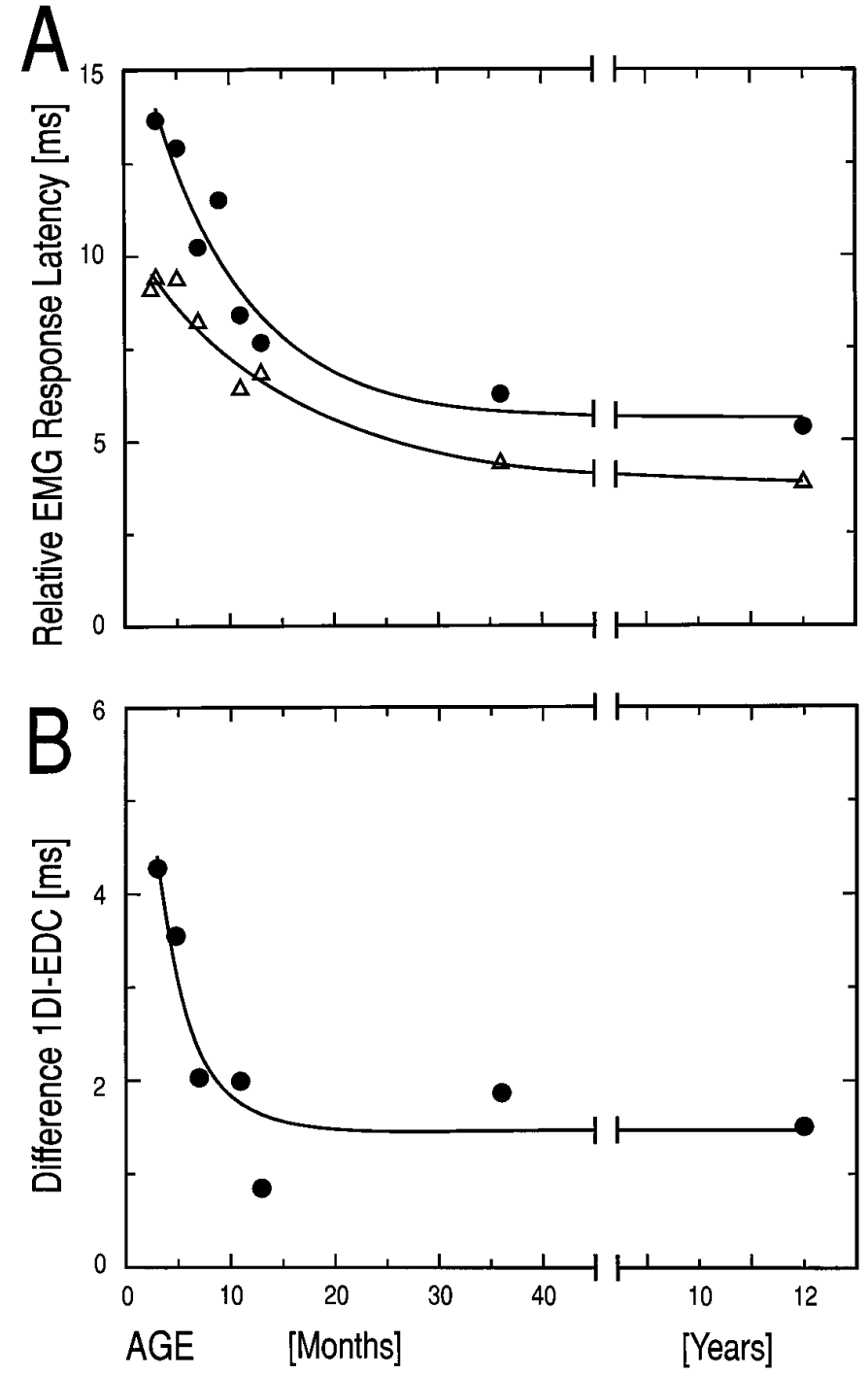

Figure 7. A, Relationship between age and normalized latency of EMG responses evoked by TMS of the motor cortex and recorded from 1DI (filled circles) and EDC (open triangles). Latencies were normalized by dividing them by the cube root of the monkey's body weight (see Materials and Methods). Equation of the best-fitted exponentials: 1DI (filled circles $), y=5.6+11.7 \exp (-0.11 x)(\tau=9.1$ months, $r=0.96)$; EDC (open triangles $), y=3.8+6.8 \exp (-0.068 x)(\tau=14.7$ months, $r=0.98)$, where $x$ is in months. $B$, Estimate of the time course of age-related decrease in $\mathrm{CV}$ of the peripheral nerves supplying 1DI and EDC. This was computed by subtracting the latency of EDC responses to TMS from that of 1DI. Equation of the best-fitted exponential: $y=1.5+7.4 \exp (-0.30 x)(\tau=3.3$ months, $r=0.92$ ).

\section{DISCUSSION}

This study has demonstrated striking changes in the physiological properties of the developing corticospinal system. The fastest fibers in this system mature move rapidly over their cranial than their spinal course, where they undergo a 10 -fold change in conduction velocity from birth to adulthood. Although slowly conducting, neonatal corticospinal axons are capable of conveying impulses at high frequency. However, TMS did not evoke EMG responses in hand muscles until $\sim 3$ months of age, which suggests the absence of effective corticospinal influence over the relevant motoneurons early in postnatal development. The final maturation in the $\mathrm{CV}$ of cortico- 


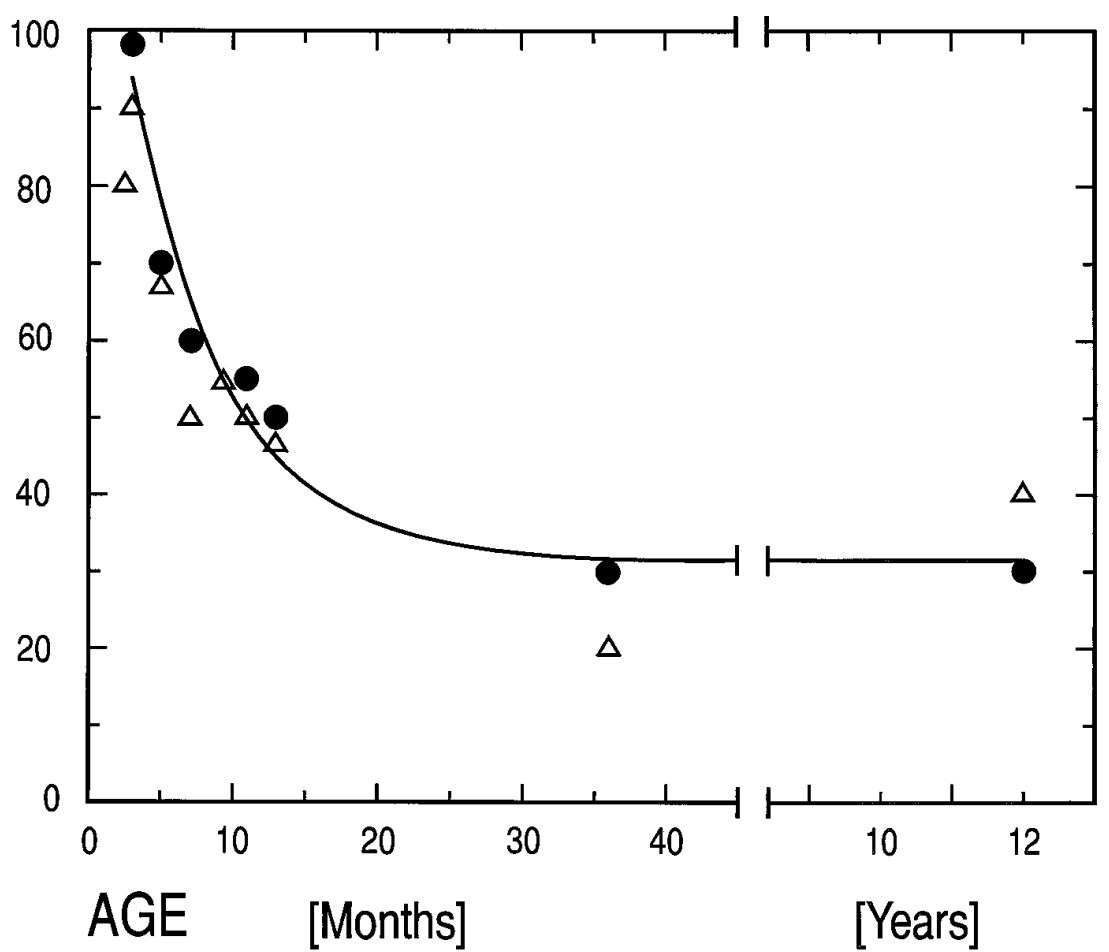

Figure 8. Age-related decrease in threshold of EMG responses recorded from 1DI (filled circles) and EDC (open triangles). The curve represents the best-fitted exponential plotted through data points obtained for 1DI $[y=31.4$ $+99.39 \exp (-0.15 x), \tau=6.5$ months, $r=0.97]$ Threshold is expressed as percent of maximum stimulator output (see Materials and Methods). No responses to TMS were obtained in the neonate or in 1-month-old cases, even at $100 \%$ output. spinal axons in the spinal cord may not occur until the third year of life. The protracted nature of development that our studies have revealed should caution investigators working on immature animals that they consider to be adults.

\section{Conduction velocity of primate corticospinal axons Adult macaques}

In the spinal cord, the mean conduction velocity of the fastest corticospinal neurons was estimated at $80.0 \mathrm{~m} / \mathrm{sec}$. This value is compatible with that estimated from the fastest antidromic responses of single corticospinal neurons recorded in motor cortex and activated from the PT [Evarts, 1965; Phillips and Porter, 1977 (p. 269); Lemon et al., 1986] but is somewhat higher than values found in the cervical segments of the macaque spinal cord by Ludolph et al. (1987) $(67.5 \mathrm{~m} / \mathrm{sec})$ and by Edgley et al. (1990) (range $66-72 \mathrm{~m} / \mathrm{sec}$ ).

For comparison, in human the $\mathrm{CV}$ of the fastest corticospinal axons within the spinal cord as measured with TMS varies between 50 and $70 \mathrm{~m} / \mathrm{sec}$ (see Boyd et al., 1986; Inghilleri et al., 1989; Herdmann et al., 1991).

Although data from only a limited number of adults were available in the present study, it is interesting to note that the fastest velocities $(83.7$ and $84.1 \mathrm{~m} / \mathrm{sec})$ were observed in the two oldest animals (10 and 12 years, cases 14 and 12). In the youngest adult (3 years, case 6 ), the $\mathrm{CV}$ was estimated at $73 \mathrm{~m} / \mathrm{sec}$. This raises the possibility that the $\mathrm{CV}$ of corticospinal neurons-and therefore their axon diameters-may continue to increase slightly with age long after the rapid changes observed during the first postnatal months. This hypothesis is confirmed by observations on the diameters of the largest corticospinal axons within the pyramid (J. Armand, S. Edgley, E. Olivier, and R. Lemon, unpublished observations).

\section{Developing macaques}

We have assumed that $\mathrm{CV}$ is a good indicator of the size and degree of myelination of corticospinal axons throughout the post- natal period. This assumption is supported by the fairly constant ratio between the $\mathrm{CV}$ of the largest corticospinal axons and their diameter in the pyramid $\left(5.2 \pm 1.1 \mathrm{~m} \cdot \mathrm{sec}^{-1} \cdot \mu \mathrm{m}^{-1}\right.$, mean $\pm \mathrm{SD}$, $n=6$ ) in monkeys aged between 2.5 months and 10 years (J. Armand, unpublished observations). Our data show that corticospinal axons within the spinal cord of the neonatal macaque conduct very slowly, with a maximum $\mathrm{CV}$ at $\sim 8 \mathrm{~m} / \mathrm{sec}$. There is then a rapid increase in the $\mathrm{CV}$ in the first postnatal months, so that by $\sim 5$ months the fastest axons now conduct at around half the speed of the adult (Fig. $4 \mathrm{~B}$ ). There is then a further protracted increase in $\mathrm{CV}$ that probably lasts for another year or more. This pattern is similar to that observed for developing rubrospinal axons in the cat (Song et al., 1995) in which, after an initial phase of rapid increase, changes in axonal $\mathrm{CV}$ match the rate of body growth, thereby keeping the central conduction time at a relatively constant value (see also Eyre et al., 1991).

The low CV of corticospinal axons in the spinal cord in the neonate indicates that they are poorly myelinated at birth; the diameter of the largest can be estimated to be only $1.5 \mu \mathrm{m}$. Although the onset of myelination of the macaque corticospinal tract at the spinal level is still unknown, the present study suggests that it may not be fully complete before 36 months of age, long after the emergence of corticospinal projections to the ventral horn (Kuypers, 1962; Galea and Darian-Smith, 1995; Armand et al., 1996b) and the apparent maturation of RIFM (Lawrence and Hopkins, 1976; Galea and Darian-Smith, 1995).

In human, although the first signs of myelination in spinal cord occur during the second trimester, myelination of the lateral corticospinal tract is clearly protracted with respect to that of other tracts (Langworthy, 1933; Niebrój-Dobosz et al., 1981; Weidenheim et al., 1992). The long latencies of EMG responses to TMS in human neonates has been partly attributed to very low corticospinal $\mathrm{CV}$, which has been estimated at $<10 \mathrm{~m} / \mathrm{sec}$ in the spinal cord (KhaterBoidin and Duron, 1991). Myelination of the human corticospinal 
tract may not be complete until well into the second decade of life (Eyre et al., 1991) (see Armand et al., 1996a).

The earlier maturation of CV in corticospinal axons at their cranial than at their spinal level (Fig. 4) indicates a rostro-caudal gradient in myelination that has also been suggested by anatomical studies in human (Niebrój-Dobosz et al., 1981; Brody et al., 1987).

\section{Age-related changes in threshold and latency of EMG responses to TMS of the motor cortex}

The present study confirms the age-related decrease in the threshold of EMG responses to TMS as reported previously in monkeys (Flament et al., 1992) and in human (Eyre et al., 1991). However, many factors may affect this threshold: they include brain size, the excitability of the corticospinal system and its ability to support repetitive discharge, the maturation of functional $\mathrm{CM}$ connections, and possible changes in motoneuronal dendritic structure and function.

\section{Brain size}

Could the lack of response in the very young animals be attributable to the fact that TMS is less effective for stimulating smaller brains (Weissman et al., 1992)? This is unlikely to explain the slow time course of the age-related changes in threshold for EMG responses because the macaque brain is known to reach its adult size at $\sim 2$ or 3 months (Holt et al., 1975). However, it is worth noting that it is at this age that EMG responses to TMS are first observed.

\section{Excitability of the corticospinal system}

In adult monkeys, TMS is known to activate corticospinal neurons both directly and indirectly (Edgley et al., 1992); slowly conducting corticospinal neurons, presumably having a small axon diameter, had a lower threshold for indirect (I wave) than direct (D wave) activation. Therefore, it may be that the small corticospinal neurons present in the neonate and youngest infants were not excited directly by TMS. If the threshold for responses to TMS were related to the size of corticospinal cells, threshold changes should parallel age-related changes in $\mathrm{CV}$ of corticospinal axons in the brain. The time constants of these changes were comparable (3.8 and 6.5 months, respectively; see Figs. 4A, 8). This hypothesis is supported further by the observation that, in human, the threshold for EMG responses to TMS does not reach adult values until the age of 16 years (Eyre et al., 1991), precisely the age at which corticospinal axon diameter is thought to attain a maximal value (see Armand et al., 1996a).

On the other hand, if the small corticospinal neurons in the infant monkey respond indirectly to TMS, such responses are likely to be influenced by the synaptic density on the immature corticospinal neuron. In the macaque monkey, the rapid phase of synaptogenesis in the motor cortex starts 2 months before birth and ends at $\sim 2$ months after birth (Rakic et al., 1985; Zecevic et al., 1989), which is just before the appearance of the first EMG responses to TMS. In addition, if TMS is able to produce multiple and successive I waves in the immature corticospinal neurons, then our data demonstrate that they are able to conduct the resulting volleys at high frequency (see Fig. 3).

\section{Maturation of CM connections}

A final and possibly critical factor concerns the response of the spinal machinery to the descending corticospinal volley that is generated by TMS. In our companion study (see Armand et al., 1996b), we have shown that there are major changes in the density of corticospinal projections during the first few months of postnatal life. In particular, the results show that direct projections to all parts of the hand muscle motor nuclei are sparse or absent at birth. Projections were clearly present at 2.5 months, although the density was still very low, and there was then a gradual increase that lasted into the second postnatal year. Age-related changes in motoneuron dendritic structure and/or electrical properties (Scheibel and Scheibel, 1970; Rose et al., 1995) are also likely to affect corticospinal influence.

Flament et al. (1992) had suggested that the higher threshold and longer latency of responses to TMS in very young monkeys might be attributable to the presence at birth of a rather weak oligosynaptic pathway linking cortex to spinal motoneurons. It might be predicted that once a significant number of direct $\mathrm{CM}$ connections were established there would be a rapid decline in threshold. We did not observe, however, any sudden age-related decrease in latency of EMG responses to TMS.

\section{Conclusion: structural and functional maturation of the corticospinal system}

Our combined anatomical and electrophysiological studies are consistent with the idea that functional $\mathrm{CM}$ connections must be established to provide the capacity for performance of fine finger movements. The connectivity provided by this system may be critical for the activation of small groups of functionally synergistic muscles required for the execution of skilled tasks (Lemon, 1993; Bennett and Lemon, 1996). Because many other parts of the sensorimotor system, including those concerned with motor learning, address the spinal cord through the motor cortex and the corticospinal system, the maturation of the CM system is but one factor in the development of hand skill. Other factors, including cognition, may well determine the limits of skill that can be achieved (Wood Jones, 1920). Nevertheless, without the appropriate connections provided by the CM system, the normal development of hand skills may well be impaired.

Although there may be important milestones in the development of the corticospinal system, such as the establishment of functional CM connections referred to above, our results stress the gradual development of the system's structure and function. Thus, in the macaque, neither the density of CM projections nor the $\mathrm{CV}$ of the fastest corticospinal axons reaches adult values until long after the first signs of the capacity to perform RIFM at $\sim 3$ months of age or, indeed, of a "mature" level of performance at $\sim 6-8$ months of age (Lawrence and Hopkins, 1976; Galea and Darian-Smith, 1995). In human, the precision grip has been shown to develop as early as 6-15 months (Watts et al., 1992), whereas corticospinal CV [estimated from central motor conduction time (CMCT) measurements] continues to increase up to 14 or 16 years (Eyre et al., 1991) (see Armand et al., 1996a).

Thus, age-related change in CV of corticospinal axons should be regarded as one of many "markers" of the developmental process and may not parallel other measures of functional maturity of the motor system. We need sensitive tests to detect subtle but important long-term improvements in motor performance. Thus, although Galea and Darian-Smith (1995) found that the timing of precision grip approached adult levels by $\sim 6$ months, careful inspection of their data reveals significant improvements that continue into the third year of life. Müller and Hömberg (1992) have shown that, in human, age-related 
changes in CMCT parallel performance on a complex task involving fast repetitive arm and hand movements. Improvement in finger movements and in the coordination of grip and loading forces (Denkla, 1973; Forrsberg et al., 1991) last well into the second decade and appear to be accompanied by neurophysiological changes in synchrony within and between motor units (Gibbs et al., 1993) and in the form and amplitude of the cutaneo-muscular reflex (Evans et al., 1990). Our results suggest that the structural and functional changes in the corticospinal system could continue to contribute to improvements in motor skill well into infancy.

\section{REFERENCES}

Armand J, Edgley SA, Lemon RN, Olivier E (1994) Protracted postnatal development of corticospinal projections from the primary motor cortex to hand motoneurones in the macaque monkey. Exp Brain Res 101:178-182.

Armand J, Olivier E, Edgley SA, Lemon RN (1996a) The structure and function of the developing corticospinal tract: some key issues. In: Hand and brain. The neurophysiology and psychology of hand movements (Wing AH, Haggard P, Flanagan JR, eds), pp 125-145. San Diego: Academic.

Armand J, Olivier E, Edgley SA, Lemon RN (1996b) The postnatal development of corticospinal projections from motor cortex to the cervical enlargement in the macaque monkey. J Neurosci 17:251-266.

Baker SN, Olivier E, Lemon RN (1994) Recording an identified pyramidal volley evoked by transcranial magnetic stimulation in a conscious macaque monkey. Exp Brain Res 99:529-532.

Bennett KMB, Lemon RN (1996) Corticomotoneuronal contribution to the fractionation of muscle activity during precision grip in the monkey. J Neurophysiol 75:1826-1842.

Bortoff GA, Strick PL (1993) Corticospinal terminations in two New World primates: further evidence that corticomotoneuronal connections provide part of the neural substrate for manual dexterity. J Neurosci 13:5105-5118.

Boyd SG, Rothwell JC, Cowan JMA, Webb PJ, Morley T, Asselman P, Marsden CD (1986) A method of monitoring function in corticospinal pathways during scoliosis surgery with a note on motor conduction velocities. J Neurol Neurosurg Psychiatry 49:251-257.

Brody BA, Kinney HC, Kloman AS, Gilles FH (1987) Sequence of central nervous system myelination in human infancy. I. An autopsy study of myelination. J Neuropathol Exp Neurol 46:283-301.

Denckla MB (1973) Development of speed in repetitive and successive finger movements in normal children. Dev Med Child Neurol 15:635-645.

Edgley SA, Eyre JA, Lemon RN, Miller S (1990) Excitation of the corticospinal tract by electromagnetic and electrical stimulation of the scalp in the macaque monkey. J Physiol (Lond) 425:301-320.

Edgley SA, Eyre JA, Lemon RN, Miller S (1992) Direct and indirect activation of corticospinal neurones by electrical and magnetic stimulation in the anaesthetized macaque monkey. J Physiol (Lond) 446:224P.

Evans AL, Harrison LM, Stephens JA (1990) Maturation of the cutaneomuscular reflex recorded from the first dorsal interosseous muscle in man. J Physiol (Lond) 428:425-440.

Evarts EV (1965) Relation of discharge frequency to conduction velocity in pyramidal tract neurons. J Neurophysiol 28:216-228.

Eyre JA, Miller S, Ramesh V (1991) Constancy of central conduction delays during development in man: investigation of motor and somatosensory pathways. J Physiol (Lond) 434:441-452.

Flament D, Hall EJ, Lemon RN (1992) The development of corticomotoneuronal projections investigated using magnetic brain stimulation in the infant macaque. J Physiol (Lond) 447:755-768.

Forssberg H, Eliasson AC, Kinoshita H, Johansson RS, Westling G (1991) Development of human precision grip. I. Basic coordination of force. Exp Brain Res 85:451-457.

Galea MP, Darian-Smith I (1995) Postnatal maturation of the direct corticospinal projections in the macaque monkey. Cereb Cortex 5:518-540.

Gibbs J, Domnesteanu C, Harrison LM, Evans AL, Stephens JA (1993) Changes in common drive to motoneurones innervating two thumb muscles studied during development in man. J Physiol (Lond) 473:14P.

Heffner RS, Masterton RB (1975) Variation in form of the pyramidal tract and its relationship to digital dexterity. Brain Behav Evol 12:161-200.

Heffner RS, Masterton RB (1983) The role of the corticospinal tract in the evolution of human digital dexterity. Brain Behav Evol 23:165-183.

Herdmann J, Dvorak J, Rathmer L, Theiler R, Peuschel K, Zenker W, Lumenta CB (1991) Conduction velocities of pyramidal tract fibres and lumbar motor nerve roots: normal values. Zent Neurochir 52:197-199.

Hinde RA, Rowell TE, Spencer-Booth Y (1964) Behaviour of socially living rhesus monkeys in their first six months. Proc Zool Soc Lond 143:609-649.

Holt AB, Cheek DB, Mellits ED, Hill DE (1975) Brain size and the relation of the primate to the nonprimate. In: Fetal and postnatal cellular growth (Cheek DB, ed), pp 23-44. New York: Wiley.

Inghilleri M, Berardelli A, Cruccu G, Priori A, Manfredi M (1989) Corticospinal potentials after transcranial stimulation in humans. J Neurol Neurosurg Psychiatry 52:970-974.

Jenny AB, Inukai J (1983) Principles of motor organization of the monkey cervical spinal cord. J Neurosci 3:567-575.

Khater-Boidin J, Duron B (1991) Postnatal development of descending motor pathways studied in man by percutaneous stimulation of the motor cortex and the spinal cord. Int J Dev Neurosci 9:15-26.

Kuypers HGJM (1962) Corticospinal connections: postnatal development in the rhesus monkey. Science 138:678-680.

Kuypers HGJM (1981) Anatomy of the descending pathways. In: Handbook of physiology. The nervous system II (Brookhart JM, Mountcastle VB, eds), pp 597-666. Bethesda, MD: American Physiological Society.

Langworthy OR (1933) Development of behavior patterns and myelinization of the nervous system in the human fetus and infant. Contr Emb 24:1-58.

Lawrence DG, Hopkins DA (1976) The development of motor control in the rhesus monkey: evidence concerning the role of corticomotoneuronal connections. Brain 99:235-254.

Lemon RN (1993) Cortical control of the primate hand. Exp Physiol 78:263-301.

Lemon RN, Mantel GWH, Muir RB (1986) Corticospinal facilitation of hand muscles during voluntary movement in the conscious monkey. J Physiol (Lond) 381:497-527.

Ludolph AC, Hugon J, Spencer PS (1987) Non-invasive assessment of the pyramidal tract and motor pathway of primates. Electroencephalogr Clin Neurophysiol 67:63-67.

Müller K, Hömberg V (1992) Development of speed of repetitive movements in children is determined by structural changes in corticospinal efferents. Neurosci Lett 144:57-60.

Müller K, Ebner B, Hömberg V (1994) Maturation of fastest afferent and efferent central and peripheral pathways: no evidence for a constancy of central conduction delays. Neurosci Lett 166:9-12.

Müller K, Hömberg V, Lenard HG (1991) Magnetic stimulation of motor cortex and nerve roots in children: maturation of corticomotoneuronal projections. Electroencephalogr Clin Neurophysiol 81:63-70.

Niebrój-Dobosz I, Fizianska A, Rafalowksa J, Sawicka E (1980) Correlative biochemical and morphological studies of myelination in human ontogenesis. I. Myelination of the spina 1 cord. Acta Neuropathol (Berl) 49:145-152.

Olivier E, Lemon R, Edgley S, Armand J (1994) Development of the primate corticospinal tract: changes in the conduction velocity of corticospinal fibres in anaesthetized neonatal and infant macaque monkeys. J Physiol (Lond) 476:27-28.

Phillips CG (1971) Evolution of the corticospinal tract in primates with special reference to the hand. In: Proceedings of the 3rd International Congress on Primatology, pp 2-23. Zurich: Karger.

Phillips CG, Porter R (1977) Corticospinal neurones: their role in movement. New York: Academic.

Porter R, Lemon RN (1993) Corticospinal function and voluntary movement. New York: Oxford UP.

Rakic P, Bourgeois J-P, Eckenhoff MF, Zecevic N, Goldman-Rakic PS (1986) Concurrent overproduction of synapses in diverse regions of the primate cerebral cortex. Science 232:232-235. 
Rose PK, Jones T, Nirula R, Corneil T (1995) Innervation of motoneurons based on dendritic orientation. J Neurophysiol 73:1319-1322.

Scheibel ME, Scheibel AB (1970) Organization of spinal motoneuron dendrites in bundles. Exp Neurol 28:106-112.

Schultz AH (1933) Growth and development. In: The anatomy of the rhesus monkey (Hartman CG, Straus WL, ed), pp 10-27. New York: Hafner.

Song WJ, Okawa K, Kanda M, Murakami F (1995) Perinatal development of action potential propagation in cat rubrospinal axons. J Physiol (Lond) 488:419-426.

Watts C, Eyre JA, Kelly S, Ramesh V (1992) Development of the pincer grasp and its relationship to the development of adult corticospinal delays in man. J Physiol (Lond) 452:273P.
Weidenheim KM, Kress Y, Isaak Epshteyn MS, Rashbaum WK, Lyman WD (1992) Early myelination in the human fetal lumbosacral spinal cord: characterization by light and electron microscopy. J Neuropathol Exp Neurol 51:142-149.

Weissman JD, Epstein CM, Davey KR (1992) Magnetic brain stimulation and brain size: relevance to animal studies. Electroencephalogr Clin Neurophysiol 85:215-219.

Wood Jones F (1920) The principles of anatomy as seen in the hand. London: Bailliére, Tindall \& Cox.

Zecevic N, Bourgeois J-P, Rakic P (1989) Changes in synaptic density in motor cortex of rhesus monkey during fetal and postnatal life. Dev Brain Res 50:11-32. 